http://jmscr.igmpublication.org/home/ ISSN (e)-2347-176x ISSN (p) 2455-0450 crossref DOI: https://dx.doi.org/10.18535/jmscr/v7i11.34

\title{
Effect of Intravenous Dexamethasone Combined with Caudal Block on Post Operative Analgesia in Children Undergoing Infraumblical Surgeries
}

\author{
Authors \\ Fauzia Shifaat $^{1 *}$,Arshi Taj ${ }^{2}$, Shazada Gani ${ }^{3}$
}

${ }^{1}$ Assistant Professor, Department of Anesthesiology \& Critical Care, Govt. Medical College, Srinagar, India

${ }^{2}$ Assistant Professor, Department of Anesthesiology \& Critical Care, Govt. Medical College, Srinagar, India

${ }^{3}$ Lecturer, Department of Anesthesiology \& Critical Care, Govt. Medical College, Srinagar, India

*Corresponding Author

Dr Fauzia Shifaat

Assistant Professor, Department of Anesthesiology \& Critical Care, Govt. Medical College, Srinagar, India

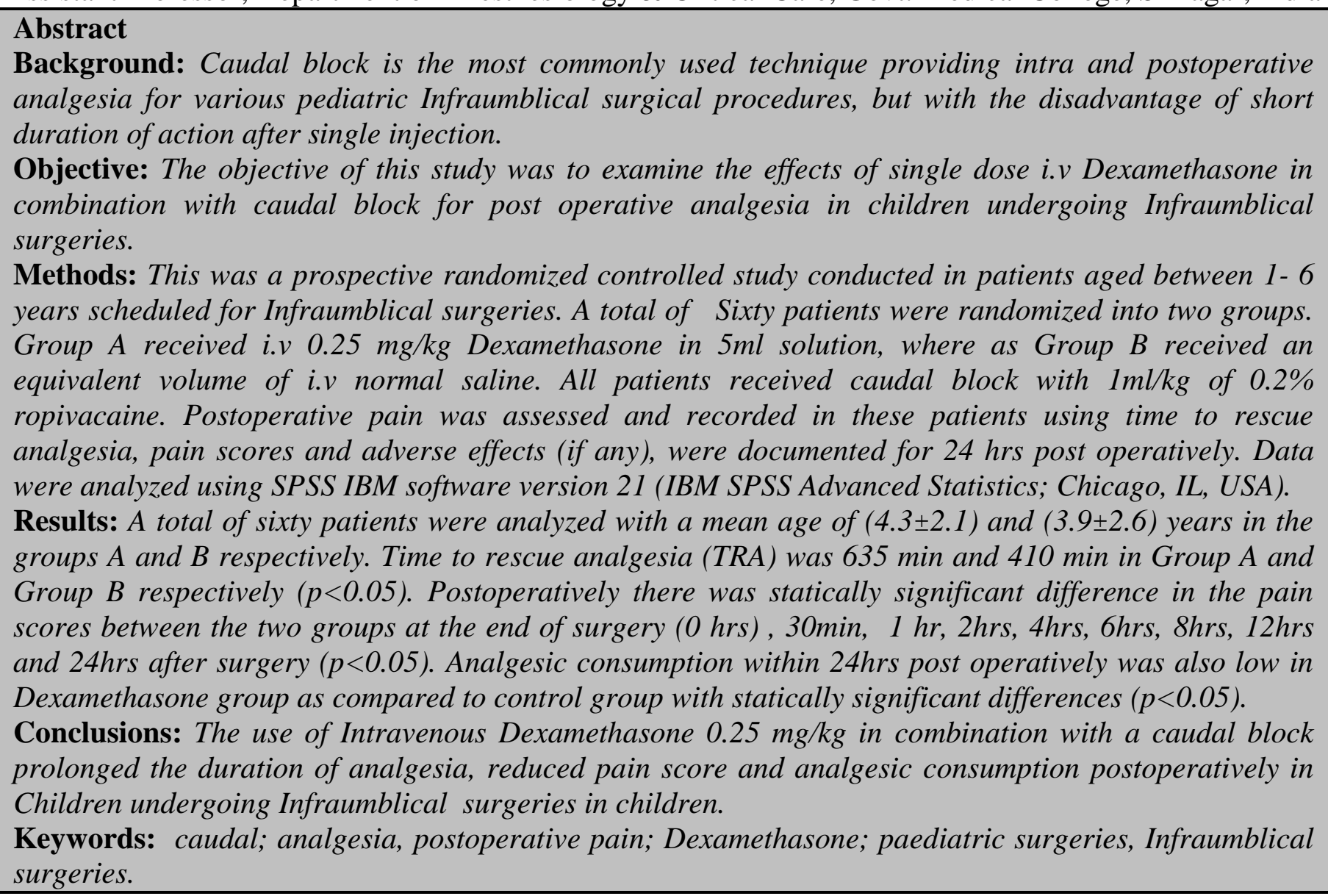

\section{Introduction}

Pediatric anesthesia has progressed immensely from the days when anaesthesiologists and specialists adjusted grown-up systems and equipment to little kids. From that point forward noteworthy improvements have happened 
including a superior comprehension with respect to torment discernment in neonates and advances in methods of general anesthesia, regional anesthesia (RA) and perioperative pain management. ${ }^{1}$

By a wide margin the most regularly utilized RA system in pediatric practice is the caudal epidural block. It is the easiest block to perform and to educate, with broad wellbeing record in childrens. Be that as it may, it has the impediment of brief term of activity after single injection. ${ }^{2}$ Prolongation of single- shot caudal block has been accomplished by the expansion of different adjuvants, for example, narcotics, ketamine, adrenaline and $\alpha 2$ agonists, yet their utility has been tested by unsatisfactory unfriendly impacts in children.- 6

Dexamethasone, a corticosteroid with solid mitigating impacts, gives postoperative absence of pain and has indicated improvement in morbidity, for example, sickness, retching, fever, and delayed oral administration in children. ${ }^{7,8}$

Fundamental organization of steroids smothers tissue levels of bradykinin and the arrival of neuropeptides from nerve endings; it likewise represses union of cyclooxygenase- 2 in fringe tissues and in the focal sensory system bringing about a decrease in prostaglandin generation which add to upgraded nociception in inflamed tissue. 9- 11 Dexamethasone administration through intravenous (IV) course alongside caudal block has been shown to significantly reduce severity of pain and rescue analgesic requirement in the post- operative period. ${ }^{12}$

The present study was aimed at examining the effects of a single dose of intravenous Dexamethasone combined with caudal block on postoperative analgesia in children undergoing Infraumblical surgeries.

\section{Methods}

The present observational study was conducted at Super specialty Hospital GMC Srinagar after getting approval from hospital's ethical committee and informed/written parental consent. A total of
Sixty American Society of Anesthesiologists physical status I and II children, aged between 1 to 6 years, undergoing Infraumblical surgeries were enrolled. Exclusion criteria exercised were children with contraindications to the caudal block such as allergy to local anaesthetic (LA) agents, coagulation disorders, pre- existing neurological disease, spine abnormalities or any infection at the local site.

During pre- operative visit, patient's age, weight and baseline vital parameters were recorded. Detailed history, general physical and systemic examinations were done. Routine laboratory investigations including haemoglobin level were carried out for all patients. All patients were kept fasting as per institutional protocol. Parents were taught to perform their role in the study and the use of visual analogue scale (VAS) for pain assessment. All children were randomly assigned into two groups of equal numbers. A person not participating in the study kept the table of random numbers and prepared all medications. On arrival of the patient to the operating room, all standard monitors were attached, and baseline heart rate [HR], mean arterial pressure (MAP) and oxygen saturation $[\mathrm{SpO} 2]$ were recorded by an investigator who was unaware of the group allocation. All patients were induced with sevoflurane $8 \%$ in oxygen with spontaneous ventilation and IV line was secured with appropriate size cannula (22 and 24 gauge) and Isolyte. $\mathrm{P}$ was started at the rate of $4 \mathrm{ml} / \mathrm{kg} / \mathrm{h}$. All the patients were premedicated with IV Fentanyl $1.5 \mu \mathrm{g} / \mathrm{kg}$. An appropriate sized classic Laryngeal mask airway (cLMA) was inserted, after giving atracurium $(0.5 \mathrm{mg} / \mathrm{kg})$ body weight, and after insertion, sevoflurane concentration was reduced to $3 \%$ with fresh gas flow of $3-4 \mathrm{~L} / \mathrm{min}$. The patient then received either Dexamethasone $0.25 \mathrm{mg} / \mathrm{kg}$ i.v in $5 \mathrm{ml}$ solution (Group A) or same volume of saline i.v. (Group B). The patients were then placed in left lateral decubitus position, and under aseptic precautions, single dose caudal block was performed with a 23-gauge short- bevelled hypodermic needle. A caudal 
anaesthetic block was then performed using 1 $\mathrm{ml} / \mathrm{kg}$ of $0.2 \%$ ropivacaine in all patients.

All the blocks were performed by the same anaesthesiologist throughout the study. The time of caudal block was recorded, and the surgery was allowed to start $05 \mathrm{~min}$ after caudal injection. Anaesthesia was maintained with sevoflurane in oxygen and Nitrous oxide $\left(\mathrm{N}_{2} 0\right)$ (50:50), and its concentration was adjusted to achieve haemodynamic changes within $20 \%$ of baseline value. Sevoflurane was discontinued at the beginning of skin closure. The neuro-muscular blockade was antagonized with neostigmine 0.05 $\mathrm{mg} / \mathrm{kg}$ and glycopyrrolate $0.01 \mathrm{mg} / \mathrm{kg}$ and LMA was removed. Then the patients were transported to the post- anaesthesia care unit. Intraoperatively vital parameters were recorded every 5 min till 30 min and every 15 min till the end of surgery.

Post- operative vitals and pain scores (using VAS score) were recorded at the end of surgery $(0 \mathrm{hr})$, 30min, $1 \mathrm{hr}$, 2hrs, 4hrs, 6hrs, 8hrs, 12hrs and $24 \mathrm{hrs}$ after surgery. The primary outcome of this study i.e., the meantime to first rescue analgesic (time interval between a caudal block to the recording of VAS score $\geq 4$ ) was recorded. Rescue analgesia was given with $15 \mathrm{mg} / \mathrm{kg}$ paracetamol intravenously. Secondary outcomes such as total doses of rescue analgesic and adverse effects such as post- operative nausea and vomiting, respiratory depression (fall in $\mathrm{SpO} 2$ of $<92 \%$ requiring supplementary $\mathrm{O} 2$ ), urinary retention, hypotension (fall in the blood pressure $>20 \%$ of the baseline value) and bradycardia (HR below 60 beats/min) were looked for and recorded.

Data were tabulated and analyzed using SPSS IBM software version 21 (IBM SPSS Advanced Statistics; Chicago, IL, USA). Results of the quantitative variables were represented as median (95\% of confidence interval) or mean (SD), and results of categorical measurements were presented in numbers or ratio. Unpaired Student's $t$ - test were applied for comparing quantitative data, and Chi- square test was applied for qualitative data. The difference was considered significant if $P<0.05$ was obtained.

\section{Results}

A total of sixty patients were recruited to the study. There were no significant differences between the two groups with regard to their age, weight, height and duration of surgery. (Table 1). No incidence of caudal block failure was observed in the study groups.

Table 1 Mean (range) or mean (SD) patient data and intraoperative characteristics. There was no difference in variables between the groups:

\begin{tabular}{|l|c|c|}
\hline Variable & $\begin{array}{c}\text { Control group } \\
\mathrm{n}=30\end{array}$ & $\begin{array}{c}\text { Dexamethasone } \\
\text { group } \mathrm{n}=30\end{array}$ \\
\hline Age $(\mathrm{months})$ & $18.6(12-70)$ & $16.8(12-71)$ \\
\hline Weight $(\mathrm{kg})$ & $11.5(4.2)$ & $10.8(3.9)$ \\
\hline Height $(\mathrm{cm})$ & $62.5(12.5)$ & $64.2(11.9)$ \\
\hline Duration of surgery & $28.5(11.4)$ & $31.2(12.5)$ \\
\hline
\end{tabular}

The doses of rescue analgesia in the PACU were significantly lower in children who received Dexamethasone compared with those who received saline (Table 2). Nine of the 30 in the control group and three of the 30 in the Dexamethasone group received rescue analgesia in PACU. The time to first rescue analgesia was significantly longer in the Dexamethasone group compared with the control group (table 2) (Fig 1).

\begin{tabular}{|l|c|c|}
\hline \multicolumn{3}{|l|}{$\begin{array}{l}\text { Table } 2 \text { Postoperative rescue analgesics } \\
\text { expressed as proportion (\%) or mean (SD). }\end{array}$} \\
\hline Variable & $\begin{array}{c}\text { Control group } \\
\mathrm{n}=30\end{array}$ & $\begin{array}{c}\text { Dexamethasone } \\
\text { group n= 30 }\end{array}$ \\
\hline $\begin{array}{l}\text { Rescue } \\
\text { analgesia }\end{array}$ & $9 / 30(30 \%)$ & $3 / 30(10 \%)$ \\
\hline $\begin{array}{l}\text { Time to first } \\
\text { rescue analgesia } \\
\text { (min) }\end{array}$ & $410(199)$ & $635(131)$ \\
\hline $\begin{array}{l}\text { Total doses of } \\
\text { rescue analgesia }\end{array}$ & $1.25(1-2)$ & $2.5(2-5)$ \\
\hline
\end{tabular}

Pain scores assessed at the PACU were significantly lower in the Dexamethasone group than in the control group (Fig. 2) 


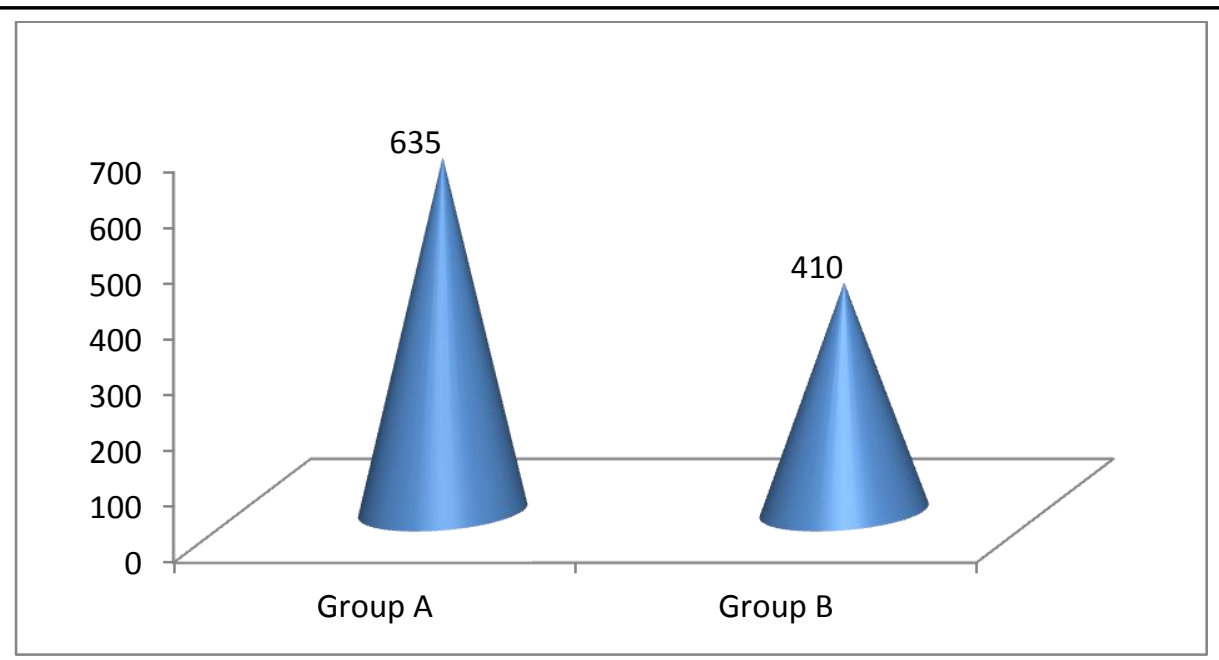

Fig 1

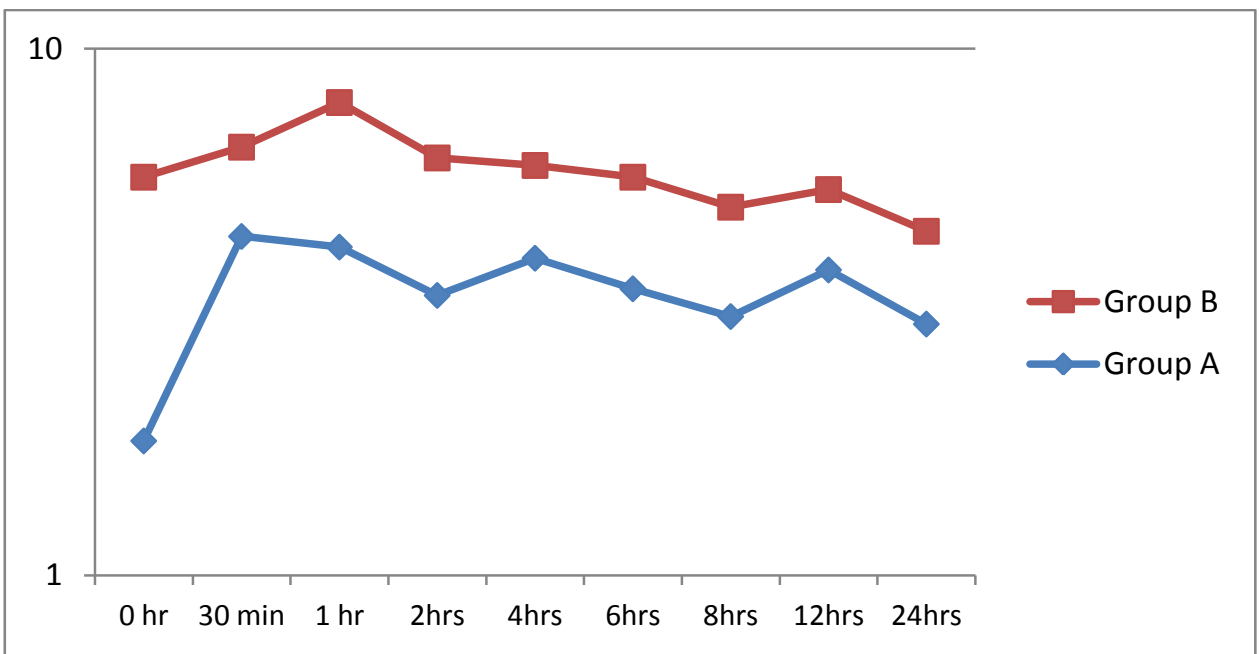

Fig 2

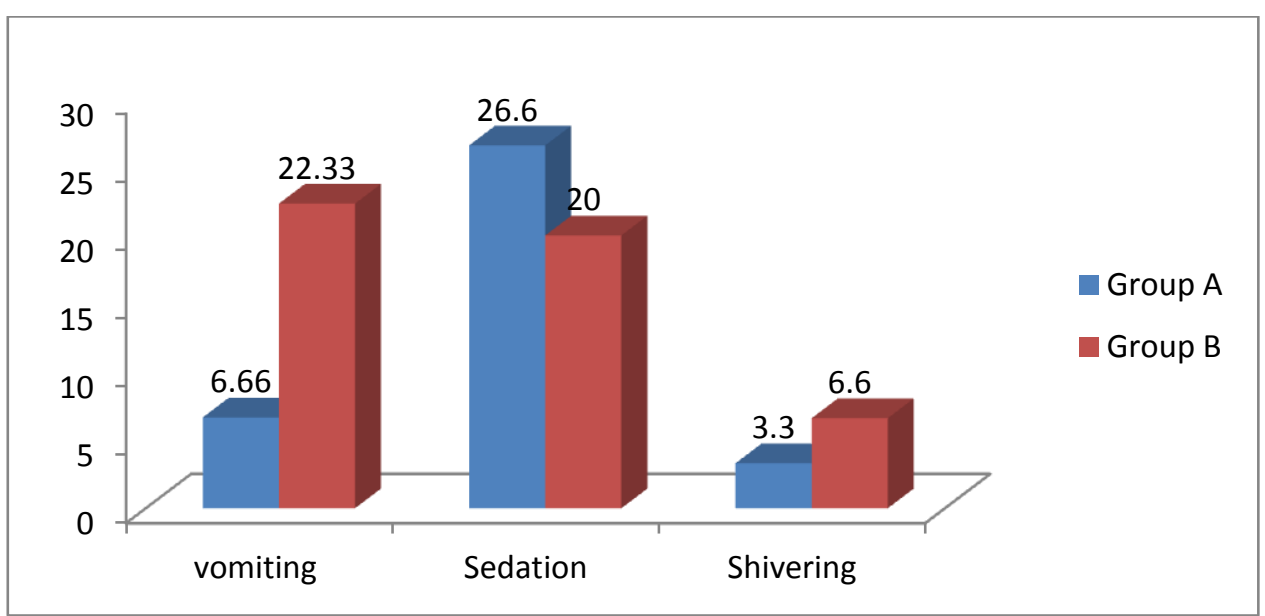

Fig 3

Although there was significant differences in the incidence of vomiting (6.66\% vs $23.33 \%$ ) among the study groups fig 3, but as per as the other adverse effects are concerned, like sedation (26.6\% vs $20 \%$ ), and shivering (3.3\% vs $6.6 \%$ ), there was no staticall significant differences between the groups Fig 3. Also there was no incidence of other adverse effects such as bradycardia, hypotension, or urinary retention in any of the groups. 


\section{Discussion}

Dexamethasone has an amazing calming activity and has exhibited decreased grimness after surgical procedure. A few investigations proposed that the expansion of dexamethasone through caudal route ${ }^{13}$ or IV route ${ }^{14-16}$ as an adjuvant to RA fundamentally diminished the post- operative pain by delaying the length of absence of pain with essentially lesser pain relieving utilization. Our study results are in line with this, in which we demonstrated that the addition of dexamethasone through IV route could significantly prolong the mean time to first rescue analgesic in children undergoing Infraumblical surgeries.

Numerous specialists have contemplated the impacts of foundational steroids in lessening postoperative pain and morbidity; be that as it may, there is no agreement with respect to their normal use, especially in kids. Results have been clashing; a few examinations showing advantage and others not. ${ }^{7,8,}{ }^{17,18}$ what's more, most distributed investigations for children's have been constrained to the otolaryngology techniques with wide scopes of Dexamethasone $(0.4-1.0 \mathrm{mg} / \mathrm{kg}$ with greatest dosages from 8 to $50 \mathrm{mg}$ ). Numerous examinations have included children's who surpassed the weight in kilograms over the greatest portion permitted; that is, there was no weight standardization of the treatment gathering. Contrasts in the portion of dexamethasone, careful and sedative methods, intraoperative narcotic use, and lack of standardization for pain scoring and management may explain in part the conflicting results reported in prior studies. Therefore, we chose a single dose of $0.25 \mathrm{mg} / \mathrm{kg}$ dexamethasone for children undergoing Infraumblical surgeries.

One of the essential advantages of dexamethasone, as revealed in past examinations, has been the abatement in postoperative nausea and vomiting. Dexamethasone may apply an antiemetic activity through prostaglandin opposition, serotonin hindrance in the gut, and arrival of endorphins. ${ }^{19}$ Our results are consistent with this, as we had only $6.6 \%$ incidence of vomiting in group A receiving i.v Dexamethasone with caudal block as compared to $23.3 \%$ in group $B$ receiving caudal block alone.

The hazard to patients of a solitary portion of Dexamethasone gives off an impression of being insignificant. We didn't measure the plasma convergences of dexamethasone, cortisol, or some other parameters related with i.v. dexamethasone in light of the fact that intrusive blood samplings for hormonal examines and long haul subsequent meet-ups were not relevant particularly in children's undergoing infraumbilical surgeries. Nonetheless, most past examinations have exhibited that for pediatric and grown-up patients experiencing surgeries, a perioperative single-dose administration of dexamethasone isn't related with a noteworthy increment in the occurrence of antagonistic impacts. ${ }^{7,8,17,18}$ also, we found no reports in the writing of entanglements from the utilization of single dose of i.v. Dexamethasone during pediatric surgeries. In this way, we propose that i.v. single admintration of Dexamethasone is a simple, straightforward, safe, and powerful adjuvant for relieving paediatric postoperative pain. Likewise, the expense of Dexamethasone is generally low, which makes routine utilize sensible.

Therefore, we conclude that the use of Intravenous Dexamethasone $0.25 \mathrm{mg} / \mathrm{kg}$ in combination with a caudal block prolonged the duration of analgesia, reduced pain score and analgesic consumption postoperatively in Children undergoing Infraumblical surgeries.

\section{References}

1. Motoyama EK, Davis PJ, editors. Special characteristics of paediatric anaesthesia. In: Smith's Anaesthesia for Infants and Children. 7th ed. Philadelphia: Elsevier; 2005.

2. Bösenberg AT, Jöhr M, Wolf AR. Pro con debate: The use of regional vs systemic analgesia for neonatal surgery. Paediatr Anaesth 2011;21:1247- 58.

3. Constant I, Gall O, Gouyet L, Chauvin M, Murat I. Addition of clonidine or fentanyl 
to local anaesthetics prolongs the duration of surgical analgesia after single shot caudal block in children. Br $\mathrm{J}$ Anaesth 1998;80:294- 8.

4. Semple D, Findlow D, Aldridge LM, Doyle E. The optimal dose of ketamine for caudal epidural blockade in children. Anaesthesia 1996;51:1170- 2.

5. Cook B, Grubb DJ, Aldridge LA, Doyle E. Comparison of the effects of adrenaline, clonidine and ketamine on the duration of caudal analgesia produced by bupivacaine in children. $\mathrm{Br} \quad \mathrm{J}$ Anaesth 1995;75:698- 701.

6. El- Hennawy AM, Abd- Elwahab AM, Abd- Elmaksoud AM, El- Ozairy HS, Boulis SR. Addition of clonidine or dexmedetomidine to bupivacaine prolongs caudal analgesia in children. Br J Anaesth 2009;103:268- 74.

7. Mohamed SK, Ibraheem AS, Abdelraheem MG. Preoperative intravenous dexamethasone combined with glossopharyngeal nerve block: role in paediatric postoperative analgesia following tonsillectomy. Eur Arch Otorhinolaryngol 2009; 266: 1815-9

8. Hanasono MM, Lalakea ML, Mikulec AA, Shepard KG, Wellis V, Messner AH. Perioperative steroids in tonsillectomy using electrocautery and sharp dissection techniques. Arch Otolaryngol Head Neck Surg 2004; 130: 917-21

9. Hargreaves KM, Costello A. Glucocorticoids suppress levels of immunoreactive bradykinin in inflamed tissue as evaluated by microdialysis probes. Clin Pharmacol Ther 1990;48:168- 78.

10. Hong D, Byers MR, Oswald RJ. Dexamethasone treatment reduces sensory neuropeptides and nerve sprouting reactions in injured teeth. Pain 1993;55:171- 81 .
11. Ferreira SH, Cunha FQ, Lorenzetti BB, Michelin MA, Perretti M, Flower RJ, et al. Role of lipocortin- 1 in the anti- hyperalgesic actions of dexamethasone. $\mathrm{Br} \quad \mathrm{J}$ Pharmacol 1997;121:883- 8.

12. Hong JY, Han SW, Kim WO, Kim EJ, Kil HK. Effect of dexamethasone in combination with caudal analgesia on postoperative pain control in day- case paediatric orchiopexy.Br $\mathrm{J}$ Anaesth 2010;105:506- 10.

13. Yousef GT, Ibrahim TH, Khder A, Ibrahim M. Enhancement of ropivacaine caudal analgesia using dexamethasone or magnesium in children undergoing inguinal hernia repair.Anesth Essays Res 2014;8:13- 9.

14. Murni Sari Ahmad A, Azarinah I, Esa K, Khairulamir Z, Hamidah I, Norsidah Abdul M. Intravenous Dexamethasone in combination with caudal block prolongs postoperative analgesia in pediatric daycare surgery. Middle East J Anaesthesiol 2015;23:177- 83.

15. Desmet M, Braems H, Reynvoet M, Plasschaert S, Van Cauwelaert J, Pottel H, et al. I.V. and perineural dexamethasone are equivalent in increasing the analgesic duration of a single- shot interscalene block with ropivacaine for shoulder surgery: A prospective, randomized, placebo- controlled study. $\mathrm{Br} \mathrm{J}$ Anaesth 2013;111:445- 52.

16. Cummings KC 3rd, Napierkowski DE, Parra- Sanchez I, Kurz A, Dalton JE, Brems JJ, et al. Effect of dexamethasone on the duration of interscalene nerve blocks with ropivacaine orbupivacaine. $\mathrm{Br}$ J Anaesth 2011;107:446- 53.

17. Vosdoganis F, Baines DB. The effect of single dose intravenous dexamethasone in tonsillectomy in children. Anaesth Intensive Care 1999; 27: 489-92 
18. Giannoni C, White S, Enneking FK. Does dexamethasone with preemptive analgesia improve paediatric tonsillectomy pain? Otolaryngol Head Neck Surg 2002; 126: 307-15

19. Bharath Srinivasan, Rakesh Karnawat, Sadik Mohammed1, Bharat Chaudhary, Anil Ratnawat, Sunil Kumar Kothari, Comparison of caudal and intravenous dexamethasone as adjuvants for caudal epidural block: A double blinded randomised controlled trial, Indian Journal of Anaesthesia, July 13, 2019 IP: 110.224.15.110. 